\title{
ADVANCES IN FABRICATION OF MONO- AND MULTIFILAMENT Ag-CLAD BSCCO SUPERCONDUCTORS*
}

\author{
U. Balachandran, A. N. Iyer, and R. Jammy \\ Energy Technology Division \\ Argonne National Laboratory \\ Argonne, IL 60439 \\ P. Haldar \\ Intermagnetics General Corporation \\ Latham, NY 12110
}

M. Suenaga

Department of Applied Science

Brookhaven National Laboratory

Upton, NY 11973

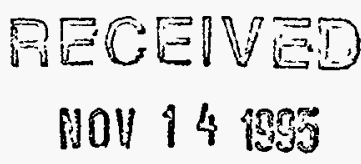

July 1995

The submitted manuscript has been authored
by a contractor of the U.S. Government
under contract No. W-31-109-ENG-38.
Accordingly, the U.S. Government retains a
nonexclusive, royalty-free license to publish
or reproduce the published form of this
contribution, or allow others to do so, for
U.S. Government purposes.

\section{DISCLAIMER}

\begin{abstract}
This report was prepared as an account of work sponsored by an agency of the United States Government. Neither the United States Government nor any agency thereof, nor any of their employees, makes any warranty, express or implied, or assumes any legal liability or responsibility for the accuracy, completeness, or usefulness of any information, apparatus, product, or process disclosed, or represents that its use would not infringe privately owned rights. Reference herein to any specific commercial product, process, or service by trade name, trademark, manufacturer, or otherwise does not necessarily constitute or imply its endorsement, recommendation, or favoring by the United States Government or any agency thereof. The views and opinions of authors expressed herein do not necessarily state or reflect those of the United States Government or any agency thereof.
\end{abstract}

INVITED manuscript submitted to Advances in Cryogenic Engineering, Volume 42, 1995.

*Work at Argonne National Laboratory and part of the work at Intermagnetics General Corporation is supported by the U.S. Department of Energy (DOE), Energy Efficiency and Renewable Energy, as part of a DOE program to develop electric power technology, under contract W-31-109-Eng-38, and at BNL under Contract No. DE-AC02-76CH0016.

\footnotetext{
DISTRIBUTION OF THIS DOCUMENT IS UNLIMITED WW
} 


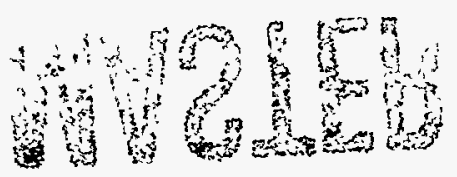




\title{
ADVANCES IN FABRICATION OF MONO- AND MULTIFILAMENT Ag- CLAD BSCCO SUPERCONDUCTORS
}

\author{
U. Balachandran, A. N. Iyer, R. Jammy ${ }^{1}$, P. Haldar J. G. Hoehn, Jr. ${ }^{2}$, and \\ M. Suenaga ${ }^{3}$ \\ IEnergy Technology Division, Argonne National Laboratory \\ Argonne, IL 60439, U.S.A. \\ 2Intermagnetics General Corporation \\ Latham, NY 12110 \\ 3 Department of Applied Science, Brookhaven National Laboratory \\ Upton, NY 11973
}

\begin{abstract}
Fabricating long lengths of robust and high-quality conductors is imperative for various applications of high- $T_{c}$ superconductors. Long lengths of mono- and multifilament $\mathrm{Ag}$-clad $\mathrm{Bi}-\mathrm{Sr}-\mathrm{Ca}-\mathrm{Cu}-\mathrm{O}$ conductors have been fabricated by the powder-in-tube technique. High values for critical current density $\left(J_{c}\right)$ have been achieved in both short- and longlength conductors. $\mathrm{J}_{\mathrm{c}}$ values up to $12,000 \mathrm{~A} / \mathrm{cm}^{2}$ have been achieved in an $850-\mathrm{m}$-long multifilament conductor. Pancake-shaped coils and test magnets fabricated from longlength conductors were characterized at various temperatures and applied magnetic fields. A magnet containing $770 \mathrm{~m}$ of high- $\mathrm{T}_{\mathrm{c}}$ conductor generated a record high field of $\approx 1 \mathrm{~T}$ at $4.2 \mathrm{~K}$ in a background field of $\approx 20 \mathrm{~T}$. In-situ tensile and bending characteristics of both mono- and multifilament conductors have also been studied. Multifilament conductors exhibited better axial strain tolerance $(\varepsilon \approx 1 \%)$ than that of monofilament conductor $(\varepsilon \approx 0.2 \%$, while retaining $90 \%$ of their initial critical current. An analysis of the results is presented, along with effects of parameters such as thickness, superconductor/Ag ratio, and microstructural details.
\end{abstract}

\section{INTRODUCTION}

Significant effort has been expended over the past few years on the development of superconducting wires and tapes for possible electric power and high-field magnet applications. Potential commercial applications of high- $\mathrm{T}_{\boldsymbol{c}}$ superconductors include motors, generators, and transmission cables. Fabricating robust and high-quality conductors is important for the various applications envisaged for high-Tc superconductors. Long lengths of Ag-clad Bi-Sr-Ca-Cu-O (BSCCO) superconductors have been successfully fabricated by the powder-in-tube (PIT) technique. The process appears to be promising for economically fabricating long lengths of flexible high- $T_{c}$ superconductors because it utilizes a processing technique similar to that currently used in the manufacture of low- $T_{C}$ superconductors. The goal is to apply the technology to devices that currently use low- $T_{\mathcal{C}}$ 
superconductors, or to new devices capable of operating at higher temperatures and/or in higher magnetic fields. ${ }^{1-6}$

Several research groups have reported high critical current density $\left(\mathrm{J}_{\mathrm{c}}\right)$ in shortlength Ag-clad BSCCO samples that were fabricated by the PIT technique and subjected to cycles of uniaxial pressing and heat treatment. In addition, $\mathrm{J}_{\mathrm{c}}$ values of tapes fabricated from BSCCO are significantly higher than those exhibited by low $-T_{c}$ superconductors, such as $\mathrm{NbTi}$ and $\mathrm{Nb}_{3} \mathrm{Sn}$, at $4.2 \mathrm{~K}$ and in high applied magnetic fields. 1-3,5,7-9 However, because uniaxial pressing is not appropriate for fabricating long lengths of conductors, a more practical approach, such as rolling, must be adopted to meet the stringent requirements of the various applications envisaged for high- $T_{c}$ superconductors. ${ }^{5}$

Using a modified processing technique, Intermagnetics General Corpioration(IGC) of Latham, NY, in collaboration with Argonne National Laboratory (ANL), have fabricated high quality mono- and multifilament BSCCO conductors in lengths of up to several hundred meters. At $77 \mathrm{~K}, \mathrm{~J}_{\mathrm{C}}$ values of $\approx 1.2 \times 10^{4} \mathrm{~A} / \mathrm{cm}^{2}$ have been achieved in a $125-\mathrm{m}$ long monocore conductor. Similar results have been obtained in long lengths of multicore conductor containing several monocore filaments. The conductors have been co-wound in parallel to form prototype pancake-shaped coils. High- $T_{c}$ superconducting magnets were then assembled by stacking the pancake-shaped coils and connecting them in series. $5,10,11$

During fabrication of coils and magnets, the tapes are subjected to both tensile and bending stresses. In addition, during service, they are subjected to large electromagnetic hoop stresses that develop because of Lorentz forces. At times, these stresses could even reach the ultimate strength of the material. Because high- $T_{c}$ superconductors are soft materials consisting of a ceramic compound and silver, which is widely used as the sheath material in the PIT process, they are unable to withstand these stresses. Cracks induced in the superconducting core because of the above mentioned stresses could lead to degradation of the current transport properties of the tapes.2,4,5,12-17 Much effort is being expended to improve strain tolerances of the tapes, either by addition of $\mathrm{Ag}$ to the superconductor core, or by using alternative sheath materials such as $\mathrm{AgNiMg}, \mathrm{AgMg}, \mathrm{Ag}$ 10 at\% $\mathrm{Cu}$, or $\mathrm{AgAl}$, or by developing multifilament conductors. ${ }^{18-22}$ This paper discusses the fabrication and characteristics of long-length conductors, high- $\mathrm{T}_{c}$ magnets, and the mechanical properties of Ag-clad BSCCO superconductors.

\section{EXPERIMENTAL PROCEDURE}

The Ag-clad BSCCO tapes were prepared by the conventional PIT technique. Appropriate amounts of $\mathrm{Bi}_{2} \mathrm{O}_{3}, \mathrm{PbO}, \mathrm{SrCO}_{3}, \mathrm{CaCO}_{3}$, and $\mathrm{CuO}$ were mixed and calcined at $800-850^{\circ} \mathrm{C}$ in air for $\approx 50 \mathrm{~h}$ to obtain a partially reacted mixture of BSCCO-2212, calcium cuprate, and other secondary phases. The characteristics of the powders were carefully monitored by differential thermal analysis, X-ray diffraction (XRD), and wet chemical analysis. To obtain a more homogeneous powder, intermittent grinding was used during calcination.

The precursor powders were packed by mechanical agitation into high-purity $\mathrm{Ag}$ tubes, lightly swaged, drawn through a series of dies, and then rolled to a final thickness of $\approx 0.1 \mathrm{~mm}$. Short lengths of tapes were cut and heat treated at $\approx 850^{\circ} \mathrm{C}$ in air with intermittent uniaxial pressing. After each thermomechanical step, the tapes were characterized by XRD, scanning electron microscopy (SEM), and critical current $\left(\mathrm{I}_{\mathrm{c}}\right)$ measurements. Transport properties of the tapes were measured by the standard four-point probe technique with a criterion of $1 \mu \mathrm{V} / \mathrm{cm}$.

Although uniaxial pressing and heat treatment cycles produced short-length tapes with the highest $J_{c}$ values, the procedure is not suitable for fabricating long length conductors. Because distribution of stresses is not uniform, repeated rolling of ceramic composites introduces cracks in the ceramic core; this, in turn, leads to degradation of transport properties. However, by carefully monitoring the rolling parameters, long-length conductors with uniform cross sections and improved transport properties have becn fabricated. These conductors have been co-wound in parallel to form pancake-shaped coils 
by the "wind-and-react" or "react-and-wind" approach. Test magnets were fabricated by stacking together and connecting a set of the pancake coils in series. The magnets were characterized at $4.2,27,64$, and $77 \mathrm{~K}$ in background fields up to $20 \mathrm{~T}$. Multifilament conductors containing 37 and 61 filaments were fabricated by stacking monocore wires in larger $\mathrm{Ag}$ tubes and then drawing and rolling them to final size.

Axial strain tolerance of mono- and multifilament (61 filaments) conductors was evaluated by subjecting the tapes to an in-situ tensile test. Retention of $I_{c}$ as a function of applied strain was measured at $77 \mathrm{~K}$ and in applied fields of 0 and $0.5 \mathrm{~T}$. In-situ bend characteristics of the conductors were obtained with a custom-designed test fixture. The tape was fixed between two movable arms mounted on a lead screw. The tapes were bent into a bath of liquid nitrogen by moving the arms toward each other by mearis of a crankshaft mechanism. The correlation between the number of turns of the crank-shaft and the radius of curvature to which the tapes were bent was pre-established at ambient temperature. The bend strain $(\varepsilon)$ was determined from the relationship

$$
\varepsilon=\mathrm{t} / 2 \mathrm{R}
$$

where $t$ is the total thickness of the tape and $R$ is the radius of curvature. The irreversible strain limit $\varepsilon_{i r r}$ is defined as that strain beyond which the decrease in the $I_{c}$ is irreversible. Bend tests were conducted on both mono- and multifilament (61 filaments) conductors at $77 \mathrm{~K}$ and zero applied field. The effect of superconductor/Ag ratio (superconductor fill factor) on the bend characteristics of monofilament conductors was also studied; monofilament conductors with fill factors of 23,30 , and $38 \%$ were used.

\section{RESULTS AND DISCUSSION}

We have used PIT technique to successfully fabricate long-length conductors with uniform cross sections and improved transport properties. At $77 \mathrm{~K}$ and zero applied field, a $\mathrm{J}_{\mathrm{c}}$ of $\approx 1.6 \times 10^{4} \mathrm{~A} / \mathrm{cm}^{2}$ has been achieved in a 125 -m-long monofilament conductor. Figure 1 shows $I_{c}$ along the length of an 850 -m-long multifilament (37 filaments) conductor. The $I_{c}$ of the conductor was $16 \mathrm{~A}$, corresponding to $\mathrm{J}_{\mathrm{c}}$ of $1.2 \times 10^{4} \mathrm{~A} / \mathrm{cm}^{2}$ at $77 \mathrm{~K}$ and zero applied field. Consistent results have been obtained from long-length monoand multifilament conductors, indicating that considerable progress has been made in their development.

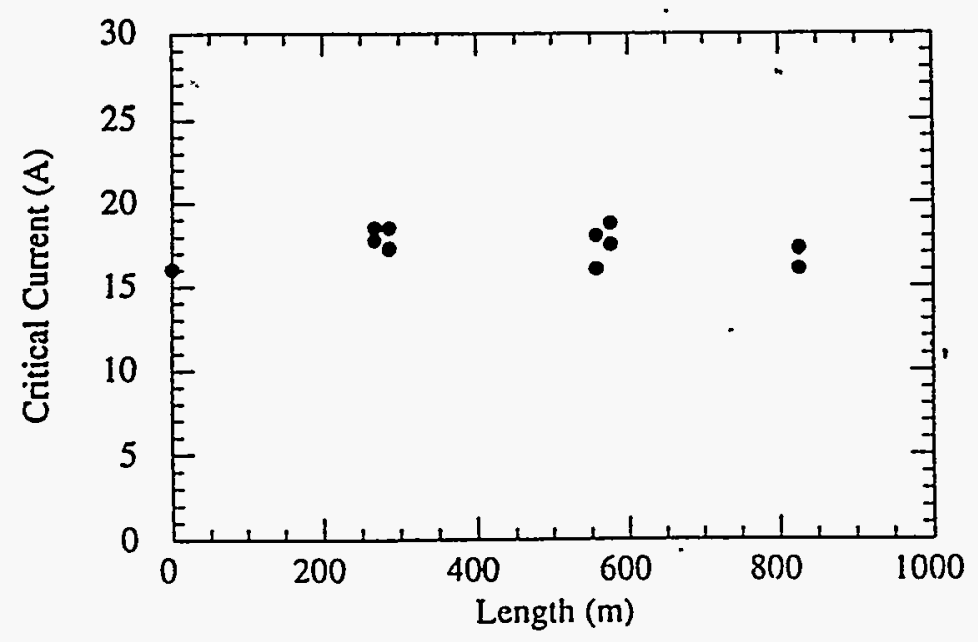

Figure 1. $\mathrm{I}_{\mathrm{C}}$ vs. length at $77 \mathrm{~K}$ of multifilament ( 37 filaments) conductor. $\mathrm{J}_{\mathrm{C}}$ of an 850 -long conductor was $=1.2 \times 10^{4} \mathrm{~A} / \mathrm{cm}^{2}$ 
Pancake-shaped coils and high- $T_{c}$ test magnets, fabricated from long-length conductors, were characterized at various temperatures and applied magnetic fields. A test magnet fabricated by stacking 10 pancake coils, with each coil containing three $16-\mathrm{m}$ lengths of BSCCO conductor, generated a record high field of $2.6 \mathrm{~T}$ at $4.2 \mathrm{~K}$ and zero applied field. At 27,64 , and $77 \mathrm{~K}$, the generated fields were $1.8,0.53$, and $0.36 \mathrm{~T}$, respectively. Total conductor length in the magnet was $\approx 480 \mathrm{~m}$. Recently, another test magnet was fabricated with eight double pancake coils. Each coil contained three $16-\mathrm{m}$ lengths of BSCCO conductor co-wound together; total conductor length was $\approx 770 \mathrm{~m}$. The magnet generated a field of $1 \mathrm{~T}$ at $4.2 \mathrm{~K}$ and $\approx 0.6 \mathrm{~T}$ at $27 \mathrm{~K}$, in a background field of $20 \mathrm{~T}$.

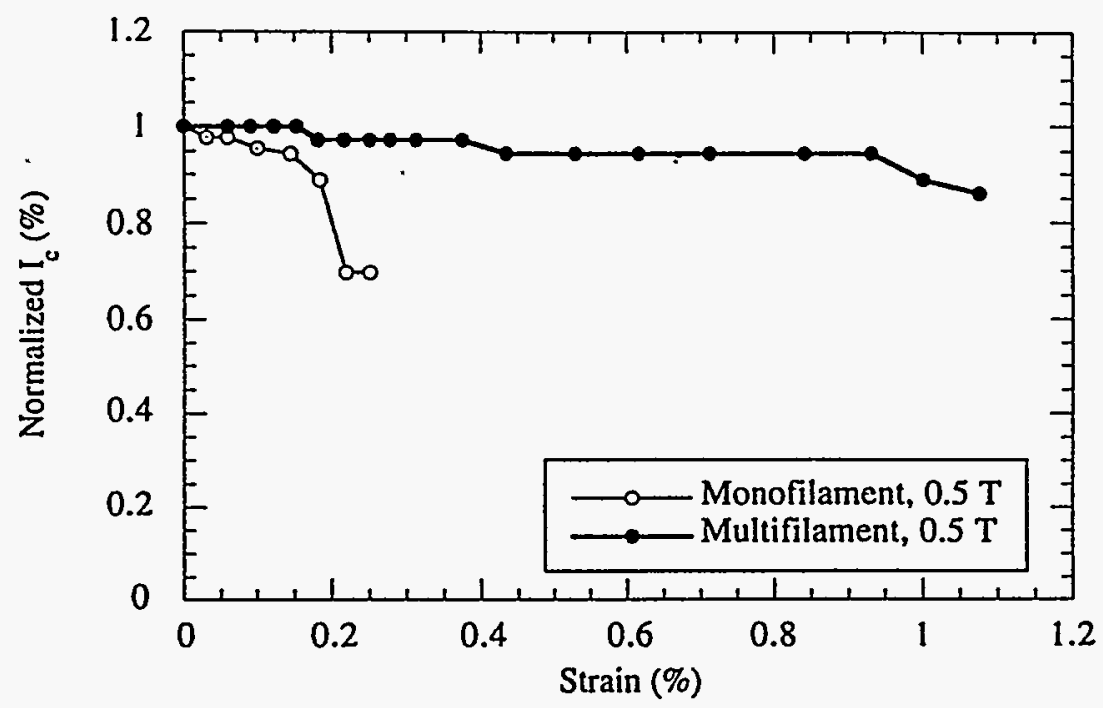

Figure 2. Normalized $\mathrm{I}_{\mathrm{C}}$ vs. strain of mono- and multifilament conductors at $77 \mathrm{~K}$ and $0.5 \mathrm{~T}$ applicd magnetic field

The results for normalized $I_{c}$ as a function of applied axial strain in an applied field of $0.5 \mathrm{~T}$ for mono- and multifilament (61 filaments) conductorsis shown in Figure 2. As seen in Figure 2, multifilament conductors appear to have better strain tolerance than monofilament conductors, retaining more than $90 \%$ of their initial $I_{c}$ at $\geq 1 \%$ strain. Whereas $\varepsilon_{\mathrm{irr}}$ for the multifilament conductor was $\approx 1 \%$, that for the monofilament conductor was $\approx 0.2 \%$. Microscopic examination of the longitudinal cross section of the monofilament conductor (Figure 3) shows fracture and delamination of the superconductor core from the $\mathrm{Ag}$ sheath. In addition, bloating of the superconductor tape, which can be attributed to the thermal gradient that is set in the material when it is removed from liquid nitrogen, was also observed. Figure 4 shows the normalized $I_{c}$ of mono- and multifilament (61 filaments) conductors as a function of bend radius. As observed by several other research groups, the drop in $I_{c}$ with decreasing bend radius is more profound in monofilament conductors than in multifilament conductors. Figure 5 shows preliminary results of the effect of superconductor/Ag ratio (superconductor fill factor) on the bend characteristics of the monofilament conductor. The plot shows that the $\varepsilon_{\text {irr }}$ for the monofilament conductor increases as superconductor fill factor decreases. For commercial development of high- $\mathrm{T}_{\mathrm{c}}$ superconductors it is important to know the strain characteristics of the tapes. The results we obtained are encouraging because they show that further improvement in mechanical properties can be achieved without compromising current transport properties. At present, effort is underway to further study the effect of superconductor/ $\mathrm{Ag}$ ratio, alternative sheath material, $\mathrm{Ag}$ doping, and packing density on the strain tolerance of BSCCO tapes. 


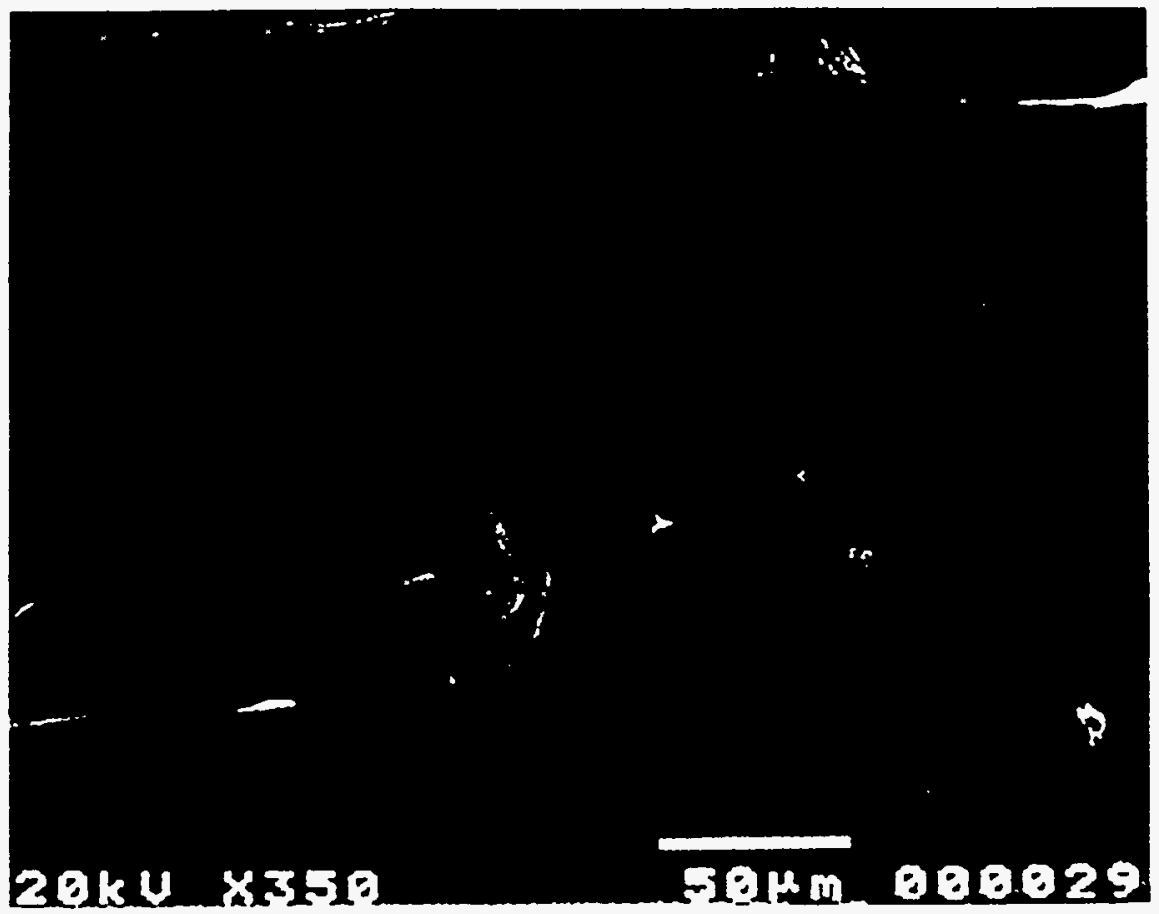

Figure 3. SEM photomicrograph of monofilament conductor subjected to in-situ tensile testing. Microscopic examination shows fracture and delamination of superconductor core from $\mathrm{Ag}$ sheath.

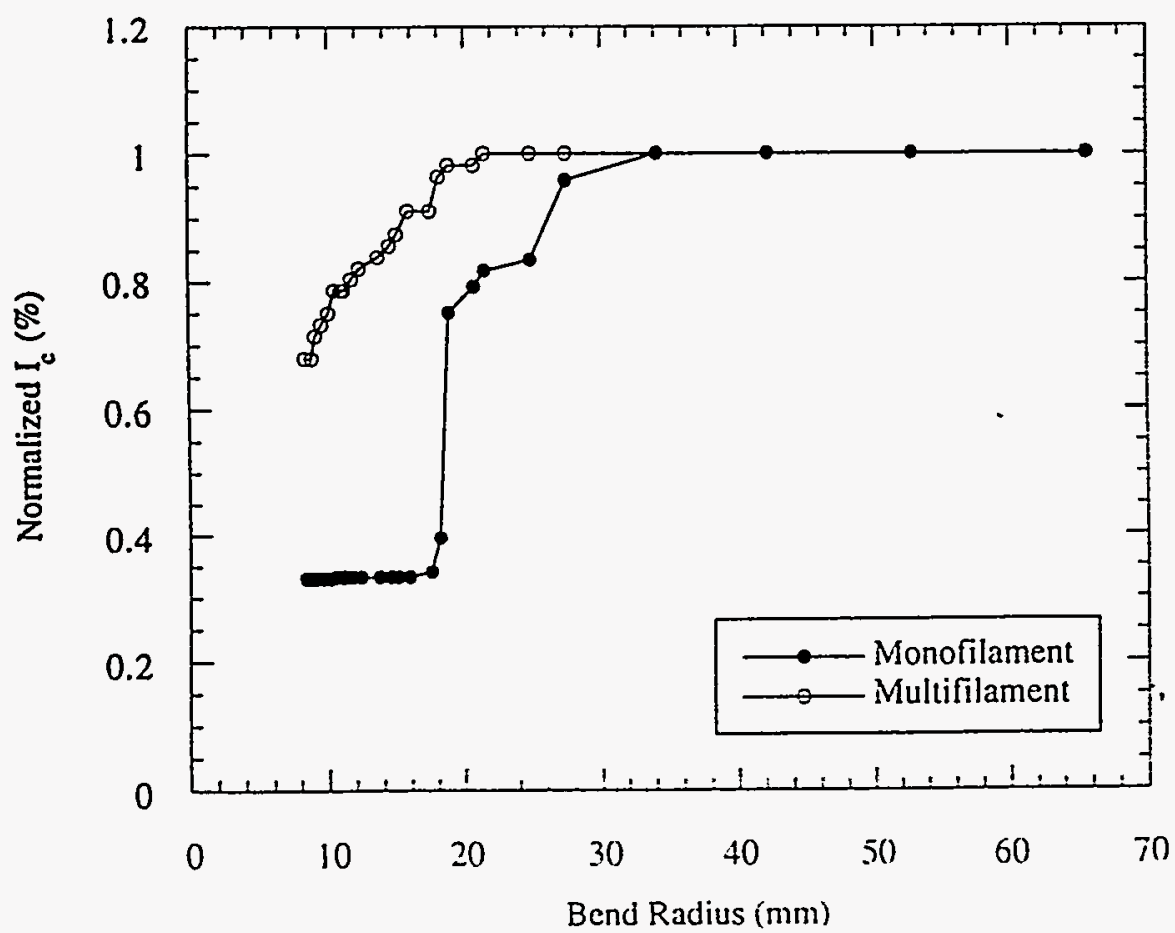

Figure 4. Normalized $I_{C}$ of mono- and multifilament conductor as a function of hend radius. 


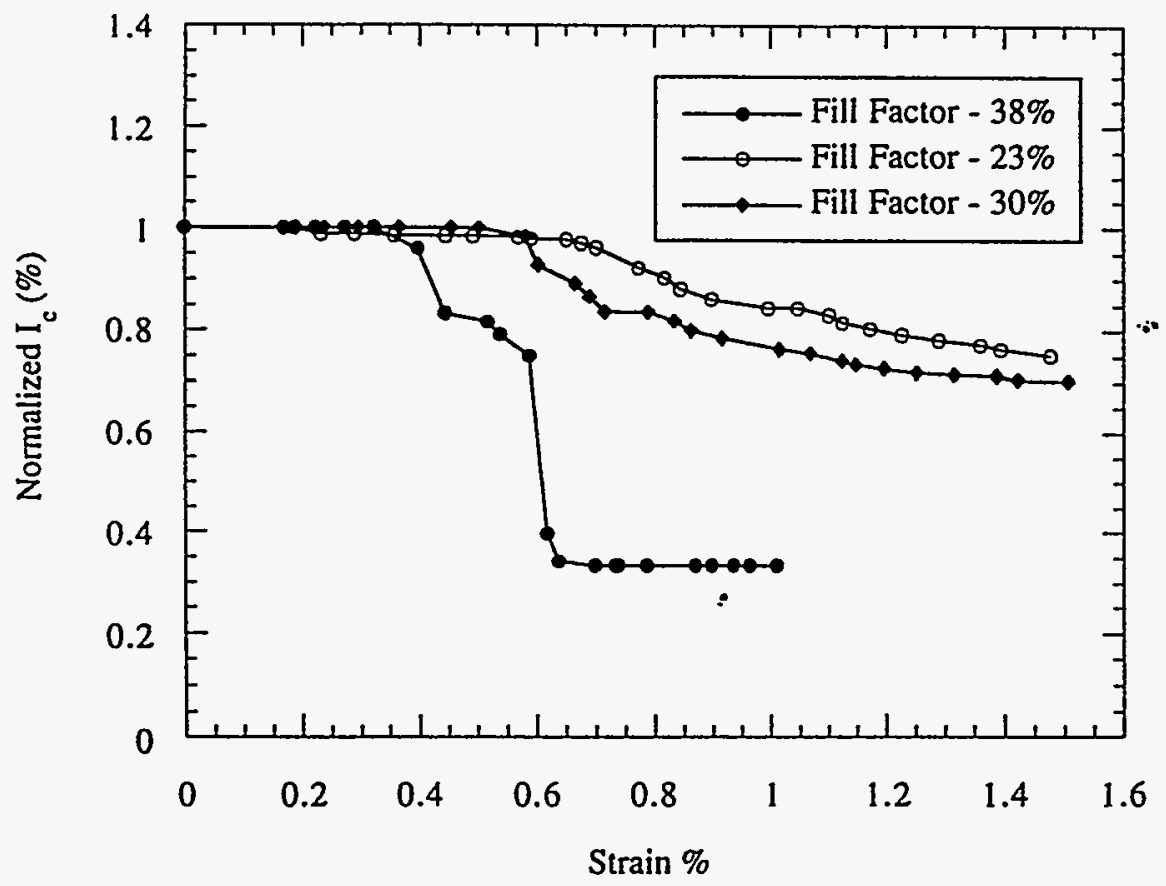

Figure 5. Normalized $I_{C}$ vs. bend strain of monofilament conductors with three superconductor fill factors.

\section{SUMMARY}

High-quality mono- and multifilament conductors up to several hundred meters in length have been successfully fabricated by the PIT technique. High- $T_{c}$ magnets were fabricated by forming pancake-shaped coils and connecting them in series. A high- $\mathrm{T}_{c}$ magnet containing $770 \mathrm{~m}$ of tape generated a field of $\approx 1 \mathrm{~T}$ at $4.2 \mathrm{~K}$ and in a background field of $20 \mathrm{~T}$. The magnets can be used, along with low- $\mathrm{T}_{\mathrm{c}}$ magnets, to form hybrid magnets for field-sensitive applications. Strain tolerance of the conductors was evaluated by subjecting them to in-situ tensile and bending tests. Tensile tests indicate that multifilament conductors exhibit better strain tolerance than monofilament conductors because they are able to retain $90 \%$ of their initial $I_{c}$ at strains $\geq 1 \%$. The effect of superconductor/ $\mathrm{Ag}$ ratio on the bending characteristics of the conductors was also evaluated. Preliminary results indicate that the irreversible strain limit of the monofilament conductor increases with decreasing superconductor fill factor.

\section{ACKNOWLEDGMENTS}

Work at Argonne National Laboratory (ANL) and part of the work at IGC is supported by the U.S. Department of Energy (DOE), Energy Efficiency' and Renewablc Energy, as part of a DOE program to develop electric power technology, under Contract W-31-109-Eng-38, and at Brookhaven National Laboratory (BNL) under Contract No. DEAC02-76CH0016. The authors thank Dr. Y. Iwasa of the Francis Bitter National Laboratory at the Massachusetts Institute of Technology for the low-temperature and highfield measurements. 


\section{REFERENCES}

I. K Sato, T. Hikata, H. Mukai, M. Ucyama, N. Shibuta, T. Kato, T. Masuda, M. Nagata, K.Iwata and T. Mitsui, IEEE Trans. Mag. 27:1231 (1991).

2. R. Flukiger, B. Hensel, A. Jermie, A. Perin and J. C. Grivel, Appl. Supercond. 1:709 (1993).

3. S. X. Dou and H. K. Liu, Supercond. Sci. Technol. 6:297 (1993).

4. J. Tenbrink, M. Wilhelm, K. Heine and H. Krauth, IEEE Trans Mag. 27:1239 (1991).

5. U. Balachandran, A. N. Iyer, J. Y. Huang, R. Jammy, P. Haldar, J. G. Hoehn, Jr., G. Galinski and L. R. Motowidlo, JOM 46:23 (1994).

6. J. Fujikami, N. Shibuta, K. Sato, H. Ishii and T. Hara, Appl. Supercond. 2:181 (1994).

7. Q. Li, K. Brodersen, H. A. Hyuler and T. Freloft, Physica C 217:360 (1993).

8. D. C. Larbalcister, X. Y. Cai, Y. Feng, H. Edelman, A. Umezawa, G. N. Riley, Jr. and W. L. Carter, Physica C 221:299 (1993).

9. M. Lelovic, P. Krishnaraj, N. G. Eror and U. Balachandran, Physica C 242:246 (1995).

10. P. Haldar, J. G. Hoehn, Jr., L. R. Motowidlo, U. Balachandran and Y. Iwasa, Adv. Cryo. Eng. 40:313 (1994).

11. L. R. Molowidlo, E. Gregory, P. Haldar, J. A. Rice, and R. D. Blaugher, Appl. Phys. Lett. 59:736 (1991).

12. U. Balachandran, A. N. Iyer, P. Haldar, J. G. Hoehn, Jr., L.'R. Motowidlo, and G. Galinski, Appl. Supercond. 2:251 (1994).

13. A. Otto, C. Craven, D. Daly, E. R. Pottburg, J. Schreiber and L. J. Masur, JOM 45:48 (1993).

14. Q. Li, J. E. Ostenson and D. K. Finnemore, J. Appl. Phys. 70:4392 (1991).

15. J. Ekin, Materials at Low Temperatures, eds. Reed and Clark, Materials Park, OH: American Society for Metals (1983).

16. S. X. Dou, H. K. Liu, Y. C. Guo, R. Bhasale, Q. Y. Hu, E. Babic, I. Kusevic, Appl. Supercond. 2:191 (1994).

17. J. W. Ekin, D. K. Finnemore, Qiang Li, J. Tenbrink and W. Carter, Appl. Phys. Lett. 61:858 (1992).

18. J. P. Singh, J. Joo, N. Vasanthamohan and R. B. Poeppel, J. Mater. Res. 8:2458 (1993).

19. J. Yau, H. K. Liu, Q. Y. Hu, N. Savvides and S. X. Dou, J. Mater. Syn. Proc. 2:45 (1994).

20. J. Schwartz, J. K. Heuer, K. C. Goretta, R. B. Poeppel, J. Guo and G. W. Raban, Jr., Appl. Supercond. 2:271 (1994).

21. S. X. Dou, Y. C. Guo, J. Yau and H. K. Liu, Supercond. Sci. Technol. 6:195 (1993).

22. T. A. Miller, J. E. Ostenson, Q. Li, L. A. Schwartzkopf, D. K. Finnemore, J. Righi, R. A. Gleixner and D. Zeigler, Appl. Plyys. Lett. 58:2159 (1991). 
, 